\section{Medical students' attitude to psychiatry}

DeAR SIRS

Dr T. H. Turner (Bulletin January, 1986, 10, 8-9) posed the question 'Whatever Happened to Stigma?' and showed that it still persists. I support his views on the need to improve the image of psychiatry and can supply some evidence to support his data on the views of medical students.

In July 1985, I surveyed the attitudes of all 72 students who attended the first morning of their first teaching block in psychiatry, which in Liverpool occurs at the end of their fourth year. This was a new course and their views could not reflect previous exposure to formal psychiatric teaching: $62.5 \%$ felt that psychiatrists were held in poor regard by most other doctors, whilst only $18.1 \%$ disagreed, $52.8 \%$ felt that psychiatrists tend to be more emotionally unstable whilst only $20.9 \%$ disagreed, and $91.7 \%$ felt psychiatric patients tend to make more emotional demands on their doctors. On the other hand $94.4 \%$ thought that psychiatric skills are essential in general practice and only $8.3 \%$ believed that within medicine psychiatry is one of the less important specialities. This last finding may be influenced by the fact that in Liverpool psychiatry is a distinct part of the final exam with its own written and clinical exams which must be passed in order to graduate. The 72 all completed the questionnaire, but 64 students failed to attend. This shortfall was attributed by the students mainly to the need to study for an imminent obstetrics and gynaecology exam which in itself is an interesting comment on their attitudes. Students' attitudes are amenable to change through experience ${ }^{1.2 .3}$ and it would therefore seem reasonable to assume that these views have been influenced by the attitudes encountered during medical school.

Yet are these attitudes really surprising when a recent leading article in the Lancet can be entitled 'Psychiatry: a discipline that has lost its way'4? Turner reminds us that there are no black and white answers to the major questions facing psychiatry in the face of the rundown of the large mental hospitals and the need to develop alternative and replacement facilities. It would appear evident that different answers may be appropriate in different situations, but as Goldberg and colleagues report: (Bulletin February 1986, 10, 36) there is increasing pressure to conform to a notional standard without adequate demonstration of the efficacy of such an approach.

We know that the failure to develop appropriate local responses will lead to an increase in the number of people with psychiatric illness receiving inadequate care. We will then find stigma increasing again and the image of psychiatry becoming more tarnished, not only with out medical peers, but with beleaguered relatives and the general public.

Would it not be appropriate for the College to be seen at the forefront of research in this field? I suggest that perhaps this could be through the new research unit acting to encourage and coordinate such service evaluations. I believe that the positive evolution of appropriate services based on informed opinion rather than dogma could do much to reduce the build up of negative attitudes which lead to increasing stigmatisation.

\section{Royal Liverpool Hospital}

IAN DAvidson

\section{Liverpool}

REFERENCES

'Wilkinson, D. G., Greer, S. \& Toone, B. K. (1983) Medical students' attitudes to psychiatry. Psychological Medicine, 13, 192.

2_- TOONE, B. K. \& GREER, S. (1983) Medical students' attitudes to psychiatry at the end of the clinical curriculum. Psychological Medicine, 13, 655-658.

3Burra, P., Leichiner, P. \& Waldron, J. J., Handporth, J. R., JARriEt, F. J. \& Amara, A. B. The A.T.P. 30-A scale for measuring medical students' attitudes to psychiatry. Medical Education, 16, 31-38.

${ }^{4}$ Anonymous (1985) Psychiatry-a discipline that has lost its way. Lancet 1, 731-2.

\section{ECT in the Netherlands}

\section{Dear Sirs}

Electroconvulsive therapy (ECT) remains a controversial subject, nowhere more so than in the Netherlands. Your readers may be interested in recent findings and developments regarding its use in that country.

In 1984 a majority of the Dutch Parliament voted in favour of retaining ECT as a therapeutic option in the treatment of psychiatric patients, a motion strongly opposed by socialist and communist deputies'. Under the public mental health guide-lines issued in February 1985, the use of ECT has been restricted to a total of ten centres (academic hospitals and a few special clinics) and for cases of 'vital' depression that have not responded to alternative forms of treatment. A second, independent medical opinion and a register of all ECT cases are also mandatory. Objecting to the narrow criteria, one deputy, a former psychiatrist, proposed that the indications for ECT be left to the discretion of the responsible specialist. His suggestion as well as one that patients be transferred to other clinics for reassessment prior to ECT were rejected by the Secretary of State.

Prior to the introduction of the 1985 guide-lines, ECT in the Netherlands had already been limited to a small group of patients with severe, refractory and often long standing depressive illnesses. Blansjaar and Nolen ${ }^{2}$ report that in 1976 only 46 patients, from a national population of 13.9 million (1978), received ECT. In the USA, UK and Denmark it is used about a hundred to two hundred times more frequently. Findings based on patients from these countries may therefore not be strictly comparable to those obtained from smaller and more highly selected Dutch samples.

For many years 'Bloemendal', serving the Dutch provinces of North and South Holland with a population of 5.5 million, was in effect the only centre in the 
Netherlands where ECT was used. In a retrospective study of its efficacy, Blansjaar and Nolen found that over the period 1981-1984, 35 non-geriatric patients had received a total of 38 courses of ECT. With the exception of four cases, the patients had severe, therapy-resistant, depression according to DSM III criteria. The mean duration of illness had been about two years. ECT proved to be effective in about $53 \%$ of cases, significantly more so in the sub-group with melancholia ('vital' depression). The effectiveness in retarded patients was particularly striking. Surprisingly, its efficacy failed to differentiate between the psychotic and non-psychotic subgroups and a significant negative correlation was found with the duration of illness.

The authors suggest that the response rate was so much lower than is usually quoted in the literature (70-80\%) due to the stricter Dutch criteria and the fact that cases which did come up for ECT had already proved resistant to other forms of therapy. In addition to the suffering entailed by severe depression, the negative correlation with illness duration would argue against delaying the use of ECT in treatment-resistant cases.

Nevertheless, it remains to be seen what impact this study and the recent legislation will have on the vociferous opinions-'like a Hiroshima in your head', according to one patient-that are expressed on this subject between the windmills!

Leicester General Hospital

Karel W. de Pauw

Gwendolen Road

Leicester

Bassetlaw District General Hospital

Worksop, Notts

REFERENCES

'Report (anon) (1984) Shocktherapie blijf onder voorwaarden gehandhaafd, De Volkskrant, 18 October.

2BLANSUAAR, B. A.\& Nolen, W. A. (1985) Elektroconvulsietherapie: Een retrospectief onderzoek naar de relatie tussen klinische parameters en het effect. Tijdschrift voor Psychiatrie, 27(9), 625-33.

\section{Draft Code of Practice - A critique}

DEAR SIRS

It was with some dismay that I recently read the Draft Code of Practice (having acquired a photocopy of same through the good offices of my secretary - for such copies are rare!) While it purports to constitute a code of practice, it in fact details in a very restrictive manner the way in which psychiatrists (inappropriately referred to in this document as rmo - small lettering!) should conduct their clinical duties, making stipulations that are often inappropriate and impractical, and indeed require individuals (e.g. nearest relatives) to make clinical judgements for which they may have no experience or training. The restrictions placed on the practice of psychiatry almost certainly disadvantages the patients by making an otherwise efficient system of care inaccessible. Moreover, it may subject a bewildered patient to a barrage of large multidisciplinary case conferences where the patient feels that their confidentiality and ability to reasonably exercise a veto on who attends is significantly compromised. In so far as it may be incumbent upon any Code of Practice to be based on fact rather than opinion, to allow a degree of latitude in the exercise of clinical judgement, avoid ambiguity and contradiction, be of such a size as to be carried upon one's person, be capable of being committed to memory, and not to contravene the rights of service users, it does seem that this draft code has been an abysmal failure.

Indeed, in as much as Section 118 of the Mental Health Act 1983 implements or sustains any Code of Practice which contravenes the human rights of individuals (future patients) in this way, should it not be taken to task in the European Court?

\section{Bryn y Neuadd and Coed Du Hospitals Clwyd}

R. V. BROWNE

\section{Dear Sirs}

At the recent Royal College Quarterly Meeting in Manchester one of the speakers, a Mental Health Commissioner, who described himself as 'not a barrister but a QC' alleged that the College Registrar was ignorant about the Draft Code of Practice in the presence of the latter after the lecture. In the same breath the QC was dismayed to find that when College members ask his advice on the Code they often do not accept his replies.

Many of us in Health Service practice are extremely used to our advice either not being sought or disregarded even when we treat people with courtesy. Maybe this is the most significant reason yet why we as trained professionals who are well experienced in these matters should form the majority not the minority of members of the Mental Health Commission and the drafters of any Code of Practice.

One fact emerged clearly from the proceedings. It seems that after 14 or so Government enquiries into mental hospitals the DHSS has commissioned a band of ambitious lawyers to write us a new textbook of psychiatry (the Code of Practice). There were a few token psychiatrists involved in the draft but, in general, although it is written in an authoritative, unsubstantiated manner, it is guaranteed to succeed as it is backed by law and thus whether we are lucky enough to get a copy or not we are legally bound by its contents.

It is just as well that the Code is published by HMSO as no commercial publisher would be naive enough to risk such a venture.

Burnley General Hospital

Michael Launer 